\title{
THE IDENTIFICATION OF ESSENTIAL NORMATIVE PERFORMANCES INDICATORS FOR ADOLESCENT: AN IMPLICATION FOR TALENT IDENTIFICATION PROGRAMME
}

\author{
A. Adnan ${ }^{1, *}$, M. R. Abdullah ${ }^{1,2}$, H. Juahir ${ }^{2}$, A. B. H. M. Maliki ${ }^{1}$, R. M. Musa ${ }^{1}$, S. M. \\ Mat-Rasid $^{2}$ and N. A. Kosni ${ }^{2}$
}
${ }^{1}$ Faculty of Applied Social Sciences, Universiti Sultan Zainal Abidin, 21300 Terengganu, Malaysia

${ }^{2}$ East Coast Environmental Research Institute (ESERI), Universiti Sultan Zainal Abidin, 21300 Terengganu, Malaysia

Published online: 08 August 2017

\begin{abstract}
This study attempts to evaluate the profile of male and female secondary school pupils for talent identification in sports. Data of anthropometric and physical were obtained from 1282 participants in a sports development program aged 13-15 years in Terengganu. Data were carried out using principal component analysis (PCA) and statistical process control (SPC). PCA revealed thirteen principal components which is standing broad jump, sit and reach, 10 meter run, 20 meter run, 40 meter run, vertical jump, max push up, 1 min sit up, predicted $\mathrm{VO}_{2}$ max, weight, height, sitting height and armspan. Such parameters that have been associated can help coaches in making athlete selection based on anthropometric and physiological component. All result demonstrated as a comprehensive method that able to provide detail on youth profile and help athlete selection for talent identification in sport.
\end{abstract}

Keywords: principal component analysis; statistical process control; talent identification.

Author Correspondence, e-mail: aleeshaadnan39@gmail.com

doi: http://dx.doi.org/10.4314/jfas.v9i2s.37 


\section{INTRODUCTION}

The interest of talent identification (TID) in sports most related in coaching and current sports science studies [3]. TID in sport generally intended to identify talent at an age as early as possible in order to provide excellent development opportunities [4]. To achieve the objective in TID, the main procedure were carried out is athlete selection process. The common traditional way of selecting athletes is depends on some experienced experts' judgments. Standards of selecting and evaluating athletes by this method are sometimes not complete and reasonable. As a result, the traditional way of evaluating athletes' talents are influenced heavily by subjective factors which bring about great deviations. The study of the traditional sport TID [11] also emphasized that the potential and talented athletes who often drop out because of the TID concept that does not fit. Currently, findings demonstrated coaches' perceptions of long-term potential can be biased by maturational variation in adolescent athletes [5]. Such perceptual bias may impact on coaches selection decisions and result in talented but late maturing athletes missing selection into development pathways. Likewise, findings in detail interviews revealed that coaches' decision making was influenced by preconceptions and various pressures to select certain players [6]. Pressures resonated within the volatile nature of their profession and career goals, the existence of competing decision-makers such as peers and parents and the tension to select players for immediate success.

Current initiative had applied scientific method in athlete selection process to replace the traditional scheme. To enable the identification of talent scientifically, most of the TID measuring and selecting young athletes based on the performance of genetically driven by a specific component. It is known that talent development and identification is a multifactorial process involving many characteristics [7]. For example, country that succeed in sports such as Australia [8] decided on the basis of the physical components of talent and performance which is believed linked to sport excellence. In addition to physical factors, the athlete's body, technical characteristics, mental state and external environment will affect the athlete's sports performance to some extent. Among the characteristics, anthropometrical and physiological factors contributed to the performances of athletes [10, 12]. There are differences being 
evident when comparing the physical and anthropometric qualities explanatory of talent. Another related studies included psychology as third component [1-2]. Various factors contributing to the athlete's performance, the most important is the athlete's physique, but at the same time the athlete's body, technical characteristics, mental state and external environment will affect the athlete's sports performance to some extent [14].

In this study, we explore the use of multivariate techniques such as PCA and SPC to provide an analytical aid in talent identification in sports. The data of anthropometric measurement and physical fitness were obtained among male and female secondary pupils in a sport development programmed year 2011 in Terengganu. Since the physical variations among adolescent is high, the identification, quantification and implementation of these anthropometric and physiological components attributes in selection decisions have a significant impact on a program's success. The new evaluation system can help experts in athlete selection in a more scientific way and can reduce the deviations caused by subjective factors. It can also help coaches in designing appropriate training for each group that have different profile. Thus, this study aim to establish scientific baseline of physical fitness and anthropometric on youth athletes.

\section{MATERIALS AND METHODS}

\subsection{Participants}

The anthropometric measurement and physical test data in this study were obtained from 909 male (age $13.6 \pm 0.57$ years, weight $38.29 \pm 10.71 \mathrm{~kg}$, height $145.17 \pm 11.98 \mathrm{~cm}$ ) and 373 females (age $13.6 \pm 0.57$ years, weight $43.40 \pm 8.37 \mathrm{~kg}$, height $151.01 \pm 6.00 \mathrm{~cm}$ ) pupils in a sport development program. The raw data was converted into a single matrix formed by 13 variables (four anthropometric components and nine physical tests) with 909 male and 373 female participants from Tunas Harapan, Terengganu. The athletes from these academies are expected to represent the state youth athletes in all sports at the state level. The coaches and the managers of the academies were informed about the purpose of the research. Writing approval was obtained, and all the players signed consent forms. 


\subsection{Anthropometric Measurement}

Anthropometrical measurements for the assessment of physical component included four variables namely weight, height, sitting height and armspan. For basic measurement, the equipment used included a stadiometer and a weighing scale. Height characteristics were measured to the nearest $0.1 \mathrm{~cm}$ and mass characteristic was measured in $\mathrm{kg}$. Armspan was measured from fingertip to fingertip while standing with the back to a flat wall and arms stretched with palms facing the investigator. The equipment required consisted of a tape measure on the wall, measured in centimeter $(\mathrm{cm})$.

\subsection{Physical Fitness Procedure}

The seven fitness test are taken into consideration in this study are as follow:

\subsubsection{Standing Broad Jump}

The participant stands behind a line marked on the ground with feet slightly apart. A two foot take-off and landing is used with swinging of the arms and bending of the knees to provide forward drive. The participant attempts to jump as far as possible, landing on both feet without falling backwards. Three attempts are allowed and the farthest was taken into account.

\subsubsection{Vertical Jump}

The investigator records the standing height of the participant with one arm fully extended upward then have the participant jump-up and touch the highest possible vane. The jump height is the difference between standing height and jumping height. Alternatively, the lowest vane had been adjusted to be at the point of the arm fully extended with both feet on the ground, and then the jump height is simply the highest vane reached. When using this device, it is very handy to have a pole for resetting the vanes without lowering the unit, and weights should be placed or otherwise stabile the base to avoid tipping. This device may be used to measure the standard vertical jump off two feet from a standing position directly underneath or a single step or run up vertical jump which is useful for testing in some sports.

\subsubsection{Speed Test}

The speed test involves running a single maximum sprint over a set distance with time recorded. After a standardized warm up, the test is conducted over 10, 20 and 40 meters. The 
starting position should be standardized, starting from a stationary position with a foot behind the starting line with no rocking movements. By using timing gates equipment, the time to run each split distance were measured $(10 \mathrm{~m}, 20 \mathrm{~m}$ and $40 \mathrm{~m})$ during the same run and then acceleration and peak velocity can also be determined.

\subsubsection{Sit and Reach}

This test involves sitting on the floor with legs out straight ahead. Feet with shoes off are placed with the soles flat against the box, shoulder-width apart. Both knees are held flat against the floor by the investigator if required. With hands on top of each other and palms facing down, the participant reaches forward along the measuring line as far as possible. After three practice reaches, the fourth reach is held for at least two seconds while the distance is recorded. Make sure there are no jerky movements and that the fingertips remain level and the legs flat.

\subsubsection{Maximum Push Up}

The aim of this test is to perform as many push-ups in the participant can. The participant starts with position arms straight with the elbows locked, body in a straight line, hands placed slightly wider than shoulder-width apart with fingers pointing forward and both feet on the floor. A foam block is placed under the chest (located at the costal arch and above the typhoid bone). The participant lowers their body until they slightly compress the foam cube and arms are at least parallel to the floor, then pushes up again. The back must be kept straight and in each extension up, the elbows should lock. Resting is allowed, though only in the up (starting) position.

\subsubsection{One Minute Sit Up}

The participants begin by sitting comfortably and start with his back straight on the mat. His knees should be bent and his feet on the mat. The participant should then place his hands on both sides of his head with his elbows pointing out to the sides. When the investigator starts the watch and says 'GO', the participant can then begin performing a sit up. From the starting position, the participant should raise his upper body of the mat by tensing his core and lifting himself up towards his knees. Hands should remain on the side of head and knees should be bent with feet placed firmly on the ground. To increase the test reliability, the investigator 
who is not recording the time should hold down the participant feet so it does not raise upwards. This prevents the participant from lifting his feet and making the sit up easier.

\subsubsection{Predicted $\mathrm{VO}_{2_{\max }}$}

The maximal multistage $20-\mathrm{m}$ shuttle run test was used to evaluate maximal aerobic capacity from maximal aerobic speed. Participants were required to run between two lines $20 \mathrm{~m}$ apart. The pace was dictated by a cassette tape emitting tones at prescribed intervals. The initial speed was set at $8.5 \mathrm{~km}$. h-1 for the first minute and was increased $0.5 \mathrm{~km}$ per hour for each subsequent minute. When runners could no longer keep up the pace by reaching the line at the time of the tone, participation was terminated and the number of laps completed was recorded (Léger and Lambert, 1982). Scores of the last stage number were converted to predict maximal oxygen uptake (VO2 max) [15]. VO2 max was expressed in ml of oxygen consumed per kilogram of body weight and per minute $\left(\mathrm{ml} . \mathrm{kg}^{-1} \cdot \mathrm{min}^{-1}\right)$. Maximal Aerobic Speed (MAS) is the lowest speed enabling you to obtain the VO2 max which the level of maximum aerobic capacity for a subject. During the test, the participants were verbally, encouraged to run as long as possible.

\subsection{The Data Analyses}

\subsubsection{Preprocessing Data}

A matrix set of male group contain 16666 matrices data (13 variables $\times 1282$ participants) were computed in this study. The total missing data in the matrices were very small $(\sim 3 \%)$ compared to the overall data recorded. For the data analysis screening, the nearest neighbor method was applied. This method examines the distance between each point and the closest point to it. The nearest neighbor method is the simplest methods, where the end points of the gaps are used as estimates of all missing values.

\subsubsection{Principal Component Analysis (PCA)}

PCA is a common technique for finding patterns in data of high dimension [13]. The idea behind of PCA is by which numbers of correlated variables are transformed into a smaller number of uncorrelated variables. Previous study applied PCA to provide indications for race walkers' classification and identified potentially important technical differences between higher and lowers skilled athletes [16]. This study mentioned two main aims of PCA to reduce 
the large quantity of data and extracts discriminatory principal components that characterize and functionally interpret different patterns. With the use of PCA it became possible to identify all the differences obtained with the parametric variables and it was still possible to identify the location in the landing cycle where the differences between tasks could be explained [17]. PCA also was functioned to analyze an athlete's technique, and then used to determine the mean posture and principal movements carried out by the athletes [18]. It can be used to compress a high dimensional dataset into a lower dimensional dataset. Recent study also revealed PCA is particularly useful when data on a number of useful variables has been gathered, and it is plausible that there is some redundancy in those variables [19]. Hence, we applied PCA to this study through the elimination of the variables that have less factor loading based on distinct eigenvalue from the set of data. The physical fitness related performance parameters were standardized through a Z-scale transformation to a mean of 0.0 and variance of 1.0 by applying Equation (1)

$Z_{i j}=\left(X_{i j}-\mu\right) / \sigma$

$Z_{i j}$ is the $j t h$ value of the standardize score of the measured variable $i$. Meanwhile, $X_{i j}$ is the observation of $j$ th on $i$ variable, $\mu$ is the mean value of the variables and $\sigma$ is the standard deviation. The Z-scale modification technique was utilized to guarantee that the distinctive relative performance parameters had similar weights in the statistical analysis procedure.

\subsubsection{Statistical Process Control (SPC)}

SPC was applied in this study to determine the baseline of the studied parameters. Then, the revised control chart without out of control data (where the out-of-control data were removed) were considered as a baseline data for each variables. SPC also applied to establish upper and lower control limits, variations in the process can be detected. Variable data control charts typically monitor the process target or mean and the process variation or range. There are a number of different types of variable data control charts, but the most common chart is the $\mathrm{x}$-bar and $\mathrm{R}$ chart. A control chart has a centerline, an upper control limit and a lower control limit. The centerline for the $\mathrm{x}$-bar chart is the process mean and the centerline for the $\mathrm{R}$ chart is the mean range. The chart most commonly used for variable data are the $\mathrm{X}$ bar chart and the $\mathrm{R}$ chart (range chart). The $\mathrm{X}$ bar charts are used to monitor the centering of process, 
and the $\mathrm{R}$ chart is used to monitor the variation in process. These charts are used together for the analysis of variable data [20]. Fig. 2 shows the calculating of the mean (X bar and R bar), Figs. 3 and 4 refer to process capability index (Cp, Cpk). In this study, the control chart was developed using the raw data to determine the out of control data.

$\overline{\bar{X}}=\frac{\sum \bar{X}}{K}$

whereas $\overline{\bar{X}}=$ Mean of means of individuals, $\sum \bar{X}=$ Sum of observation and $K=$ Number of subgroups size. The X-bar charts are used to monitor the centering of process, and the R chart is used to monitor the variation in process. Here is the information of calculation the $\mathrm{Cp}$ and Cpk:

$\mathrm{Cp}=(\mathrm{USL}-\mathrm{LSL}) / 6 \sigma$

where $\mathrm{Cp}=$ Process average or $\overline{\mathrm{x}}, \mathrm{USL}=$ Upper Specification Limit, $\mathrm{LSL}=$ Lower Specification Limit and $\sigma_{\text {est }}=$ Standard Deviation .

The measurement that assesses process centering in addition to spread or variability is Cpk. Think of $\mathrm{Cpk}$ as a $\mathrm{Cp}$ calculation that is handicapped by considering only the half of the distribution that is closest to the specification. Cpk is calculated as follows:

Process Capability Index Cpk = Minimum of Cpl

$\mathrm{Cpl}=(\mathrm{Xbar}-\mathrm{LSL}) / 6 \sigma \mathrm{Cpu}=(\mathrm{USL}-\mathrm{Xbar}) / 3 \sigma$

where $\sigma=$ Standard Deviation, $\mathrm{X}$ bar $=$ Mean find in the $\mathrm{X}$ bar chart, USL $=$ Upper specification Limit and LSL $=$ Lower Specification Limit.

\section{RESULTS AND ANALYSIS}

Prior of the main analysis, measurement of the sampling adequacy is shown by the KMO as projected in Table 1. This test was implemented to determine the adequacy of the sampling to quantify as well as to make a reasonable interpretation based on the data gathered. Similarly, the test was conducted to ensure that the variables are not related to each other. From the table, the KMO value shows 0.89 and 0.77 which contributed $89 \%$ and $69 \%$ sampling adequacy for both the male and female athletes respectively and $\mathrm{VO}_{2} \max (0.75)$ together with the three categories of distance speed test with strong negative factor loading s 10m (-0.86), 20m (-0.92) 
and 40m (-0.91) respectively.

Table 1. Kaiser-Meyer-Olkin (KMO) measure of sampling adequacy

\begin{tabular}{ccc}
\hline Components & Male & Female \\
\hline Weight & 0.902 & 0.768 \\
Height & 0.811 & 0.616 \\
Sitting Height & 0.862 & 0.634 \\
Armspan & 0.856 & 0.649 \\
Standing Broad Jump & 0.947 & 0.931 \\
10 Meter Run & 0.905 & 0.831 \\
20 Meter Run & 0.923 & 0.744 \\
40 Meter Run & 0.875 & 0.828 \\
Vertical Jump & 0.968 & 0.933 \\
Sit and Reach & 0.721 & 0.564 \\
Max Push Up & 0.875 & 0.865 \\
1 Min Sit Up & 0.974 & 0.946 \\
VO2 Max & 0.904 & 0.891 \\
KMO & 0.887 & 0.765 \\
\hline
\end{tabular}

Therefore, based on this results it is evident that there is no multicollinearity observed among the original variables and that enabled us to proceed further with the statistical analysis namely PCA and SPC. Based on PCA without rotation, the eigenvalue for the male and female athletes was determined. From the figure, it can be observed that two components were identified by the PCA. Fig. 1 shows that the first three PC's has eigenvalue. For both male and female athletes as the most essential due to their higher eigenvalues greater than 1 ( $>$ 1). These components were retained and utilized as an input variable for further analysis. 


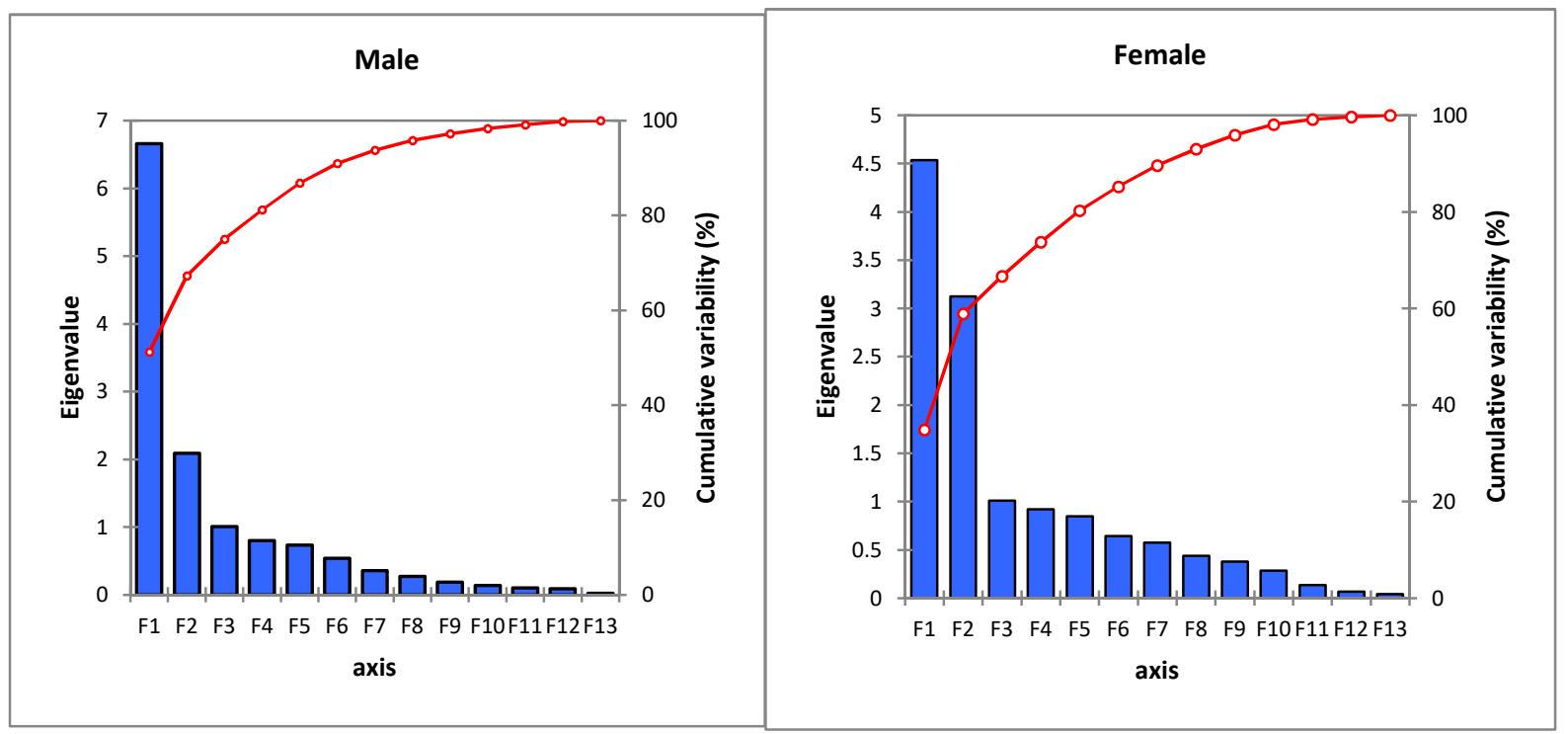

Fig.1. Scree plots for PCA

Table 2 reveals the PCA after varimax rotation carried out for both the male and female athletes. It can be observed from the figure that VF1, VF2 and VF3 contributed to about $75.02 \%$ of the total data set and the variability of $33.23 \%, 31.23$ and $10.55 \%$ for male athletes. However, the VF1, VF2 and VF3 for women athletes contributed to about $66.69 \%$ of the whole data set with a variability of $33.12 \%, 24.72 \%$ and $8.84 \%$ respectively. It can be seen from the table that from VF1, three components out of the thirteen performance indicators shows string negative factor loading where the factor loading is greater than 0.7 which the three distance speed test namely $10 \mathrm{~m}, 20 \mathrm{~m}$ and $40 \mathrm{~m}$ run has strong negative factor loading is $-0.88,-0.87$ and -0.89 for the male category. While for the female category, the results had shown that two additional parameters were taken into consideration as strong factor loading. These two parameters with strong factor loading namely standing broad jump (0.74). The new variable called VF1 can be rename as athlete's performances indicators for both categories. From VF2 of the same athletes identified four components with a positive higher factor loading and VF3 showed that one component satisfied 0.70 factor loading. Nevertheless, VF1 from the women athletes identified five components with higher positive factor loading while VF2 from the same group identified four components and VF3 with one component with a positive higher factor loading. These indicators are then classified as the essential components that are mainly required for the performance in anthropometric and physical fitness across the male and female athletes. 
Table 2. Varifactors after varimax rotation and the possible source of the components in the

\begin{tabular}{|c|c|c|c|c|c|c|}
\hline \multirow{2}{*}{ Parameters } & \multicolumn{3}{|c|}{ Male } & \multicolumn{3}{|c|}{ Female } \\
\hline & VF1 & VF2 & VF3 & VF1 & VF2 & VF3 \\
\hline Weight & 0.01 & 0.93 & -0.01 & -0.18 & 0.81 & 0.14 \\
\hline Height & 0.38 & 0.89 & 0.08 & 0.17 & 0.92 & -0.10 \\
\hline Sitting Height & 0.29 & 0.90 & 0.14 & 0.08 & 0.87 & 0.22 \\
\hline Armspan & 0.35 & 0.89 & 0.09 & 0.17 & 0.86 & -0.10 \\
\hline \multicolumn{7}{|l|}{ Standing Broad } \\
\hline Jump & 0.69 & 0.36 & 0.34 & 0.74 & 0.12 & 0.18 \\
\hline 10 Meter Run & -0.88 & -0.16 & 0.01 & -0.86 & -0.04 & -0.14 \\
\hline 20 Meter Run & -0.87 & -0.28 & -0.06 & -0.92 & -0.06 & -0.13 \\
\hline 40 Meter Run & -0.89 & -0.28 & -0.11 & -0.91 & -0.06 & -0.14 \\
\hline Vertical Jump & 0.66 & 0.51 & 0.22 & 0.57 & 0.12 & 0.14 \\
\hline Sit and Reach & 0.03 & 0.35 & 0.68 & 0.15 & 0.16 & 0.86 \\
\hline Max Push Up & 0.26 & -0.11 & 0.76 & 0.31 & -0.35 & 0.40 \\
\hline 1 Min Sit Up & 0.44 & 0.29 & 0.09 & 0.49 & -0.03 & -0.25 \\
\hline VO2 Max & 0.68 & -0.11 & 0.32 & 0.75 & -0.14 & 0.01 \\
\hline Eigenvalue & 6.66 & 2.09 & 1.01 & 4.54 & 3.13 & 1.01 \\
\hline Variability (\%) & 33.235 & 31.239 & 10.550 & 33.126 & 24.724 & 8.846 \\
\hline Cumulative \% & 33.235 & 64.473 & 75.023 & 33.126 & 57.850 & 66.696 \\
\hline
\end{tabular}

Development of the capabilities index was solicited by employing statistical process control (SPC). Analysis of the SPC is further analysis using input given by PCA due to gender categories. Selection of the significant parameters is further analyzed by gender separately. Based on the Fig. 2, it projected upper control limit (UCL), center line (CL) and lower control limit (LCL) for each significant parameters. 
Table 3. Results of SPC

\begin{tabular}{|c|c|c|c|c|c|}
\hline \multirow{2}{*}{ Fitness Test } & \multicolumn{5}{|c|}{ SPC } \\
\hline & Gender & Range & $\mathbf{U C L}$ & $\mathbf{C L}$ & $\mathbf{L C L}$ \\
\hline \multirow{2}{*}{ Weight (kg) } & Male & $25-50$ & 32.01 & 36.29 & 24.59 \\
\hline & Female & $30-55$ & 59.81 & 43.39 & 26.97 \\
\hline \multirow{2}{*}{ Height $(\mathrm{cm})$} & Male & $135-155$ & 133.64 & 145.17 & 133.64 \\
\hline & Female & $142-160$ & 139.43 & 151.01 & 162.90 \\
\hline \multirow{2}{*}{ Sitting height (cm) } & Male & $68-80$ & 80.03 & 73.62 & 67.21 \\
\hline & Female & $72-82$ & 84.18 & 76.87 & 69.56 \\
\hline \multirow{2}{*}{ Armspan $(\mathrm{cm})$} & Male & $135-160$ & 160.87 & 147.07 & 133.27 \\
\hline & Female & $142-162$ & 165.99 & 152.50 & 139.02 \\
\hline \multirow{2}{*}{ Standing broad jump $(\mathrm{cm})$} & Male & $130-180$ & 189.08 & 158.07 & 127.07 \\
\hline & Female & $110-160$ & 173.48 & 136.37 & 99.26 \\
\hline \multirow{2}{*}{10 meter run $(\mathrm{s})$} & Male & $1.90-2.35$ & 2.37 & 2.12 & 1.88 \\
\hline & Female & $2.05-2.45$ & 2.53 & 2.25 & 1.98 \\
\hline \multirow{2}{*}{20 meter run (s) } & Male & $3.4-4.2$ & 4.18 & 3.77 & 3.37 \\
\hline & Female & $3.4-4.2$ & 4.18 & 3.77 & 3.37 \\
\hline \multirow{2}{*}{40 meter run (s) } & Male & $6.3-7.8$ & 7.95 & 7.09 & 6.24 \\
\hline & Female & $7.0-8.5$ & 8.89 & 7.76 & 6.62 \\
\hline \multirow{2}{*}{ Vertical jump (cm) } & Male & $30-45$ & 38.21 & 45.78 & 30.64 \\
\hline & Female & $32-44$ & 47.23 & 37.82 & 28.42 \\
\hline \multirow{2}{*}{ Sit and reach $(\mathrm{cm})$} & Male & $22-36$ & 36.83 & 28.89 & 20.95 \\
\hline & Female & $20-35$ & 39.97 & 28.47 & 16.99 \\
\hline \multirow{2}{*}{ Max push-up (reps) } & Male & $5-25$ & 27.81 & 14.65 & 1.49 \\
\hline & Female & $5-25$ & 29.01 & 13.82 & 1.37 \\
\hline \multirow{2}{*}{1 min sit-up (reps) } & Male & $5-25$ & 25.94 & 13.95 & 1.96 \\
\hline & Female & $5-23$ & 26.02 & 13.05 & 0.07 \\
\hline \multirow{2}{*}{$\mathrm{VO}_{2} \max (\mathrm{ml} / \mathrm{kg} / \mathrm{min})$} & Male & $23-40$ & 40.30 & 30.99 & 21.69 \\
\hline & Female & $20-31$ & 33.29 & 25.17 & 17.04 \\
\hline
\end{tabular}


In the current study, the value of Upper Control Limit (UCL), Average Control Limit (ACL) and Lower Control Limit (LCL) were identified for each parameters. For male athletes, by weight $(\mathrm{UCL}=32.01 \mathrm{~kg}, \mathrm{ACL}=36.29 \mathrm{~kg}, \mathrm{LCL}=24.59 \mathrm{~kg})$, height $(\mathrm{UCL}=133.64 \mathrm{~cm}, \mathrm{ACL}=$ $145.17 \mathrm{~cm}, \mathrm{LCL}=133.64 \mathrm{~cm})$, Sitting height $(\mathrm{UCL}=80.03, \mathrm{ACL}=73.62, \mathrm{LCL}=67.21)$, Sitting height $(\mathrm{UCL}=80.03, \mathrm{ACL}=73.62, \mathrm{LCL}=67.21)$, armspan $(\mathrm{UCL}=160.87, \mathrm{ACL}=$ 147.07, $\mathrm{LCL}=133.27)$, Standing broad jump $(\mathrm{UCL}=189.08, \mathrm{ACL}=158.07, \mathrm{LCL}=127.07)$, 10 meter run $(\mathrm{UCL}=2.37 \mathrm{~m}, \mathrm{ACL}=2.12 \mathrm{~m}, \mathrm{LCL}=1.88 \mathrm{~m}), 20$ meter run $(\mathrm{UCL}=4.18 \mathrm{~m}, \mathrm{ACL}$ $=3.77 \mathrm{~m}, \mathrm{LCL}=3.37 \mathrm{~m}), 40$ meter run $(\mathrm{UCL}=7.95 \mathrm{~m}, \mathrm{ACL}=7.09 \mathrm{~m}, \mathrm{LCL}=6.24 \mathrm{~m})$, Vertical jump $(\mathrm{ACL}=38.21, \mathrm{UCL}=45.78, \mathrm{LCL}=30.64)$, Sit and reach $(\mathrm{UCL}=36.83, \mathrm{ACL}=28.89$, $\mathrm{LCL}=20.95)$, Max push-up $(\mathrm{UCL}=27.81, \mathrm{ACL}=14.65, \quad \mathrm{LCL}=1.49), 1 \mathrm{~min}$ sit-up (UCL $=25.94, \mathrm{ACL}=13.95, \mathrm{LCL}=1.96), \mathrm{VO} 2 \max (\mathrm{UCL}=40.30, \mathrm{ACL}=30.99, \mathrm{LCL}=21.69) . \mathrm{In}$ the other hand, for female athletes, Weight $(\mathrm{UCL}=59.81 \mathrm{~kg}, \mathrm{ACL}=43.39 \mathrm{~kg}, \mathrm{LCL}=26.97 \mathrm{~kg})$, height $(\mathrm{UCL}=139.43 \mathrm{~cm}, \mathrm{ACL}=151.01 \mathrm{~cm}, \mathrm{LCL}=162.9 \mathrm{~cm})$, Sitting height $(\mathrm{UCL}=84.18$, $\mathrm{ACL}=76.87, \mathrm{LCL}=69.56), \operatorname{armspan}(\mathrm{UCL}=165.99, \mathrm{ACL}=152.50, \mathrm{LCL}=139.02)$, Standing broad jump $(\mathrm{UCL}=173.48, \mathrm{ACL}=136.37, \mathrm{LCL}=99.26), 10$ meter run $(\mathrm{UCL}=$ $2.53 \mathrm{~m}, \mathrm{ACL}=2.25 \mathrm{~m}, \mathrm{LCL}=1.98 \mathrm{~m}), 20$ meter run $(\mathrm{UCL}=4.18 \mathrm{~m}, \mathrm{ACL}=3.77 \mathrm{~m}, \mathrm{LCL}=$ $3.37 \mathrm{~m}), 40$ meter run $(\mathrm{UCL}=8.89, \mathrm{ACL}=7.76 \mathrm{~m}, \mathrm{LCL}=6.62 \mathrm{~m})$, Vertical jump $(\mathrm{UCL}=$ 47.23, $\mathrm{ACL}=37.82, \mathrm{LCL}=28.42)$, Sit and reach $(\mathrm{UCL}=39.97, \mathrm{ACL}=28.47, \mathrm{LCL}=16.99)$, Max push-up $(\mathrm{UCL}=29.01, \mathrm{ACL}=13.82$, and $\mathrm{LCL}=1.37), 1 \mathrm{~min}$ sit-up $(\mathrm{UCL}=26.02, \mathrm{ACL}$ $=13.05, \quad \mathrm{LCL}=0.07)$ and $\mathrm{VO} 2 \max (\mathrm{UCL}=33.29, \mathrm{ACL}=25.17, \mathrm{LCL}=17.04)$. As a results, it just reflect the potential of variation in the relative performances from the equivalent indicators relevant to the talent identification program. This finding noted the novelty of the normative baseline. Similarly, other studies projected the baseline by applying mean and average which is reflected only descriptive of the indicators. Control limit benificiancy in this study highlighted the capability index with natural variation for the establishing normative baseline based on the significant parameters. 

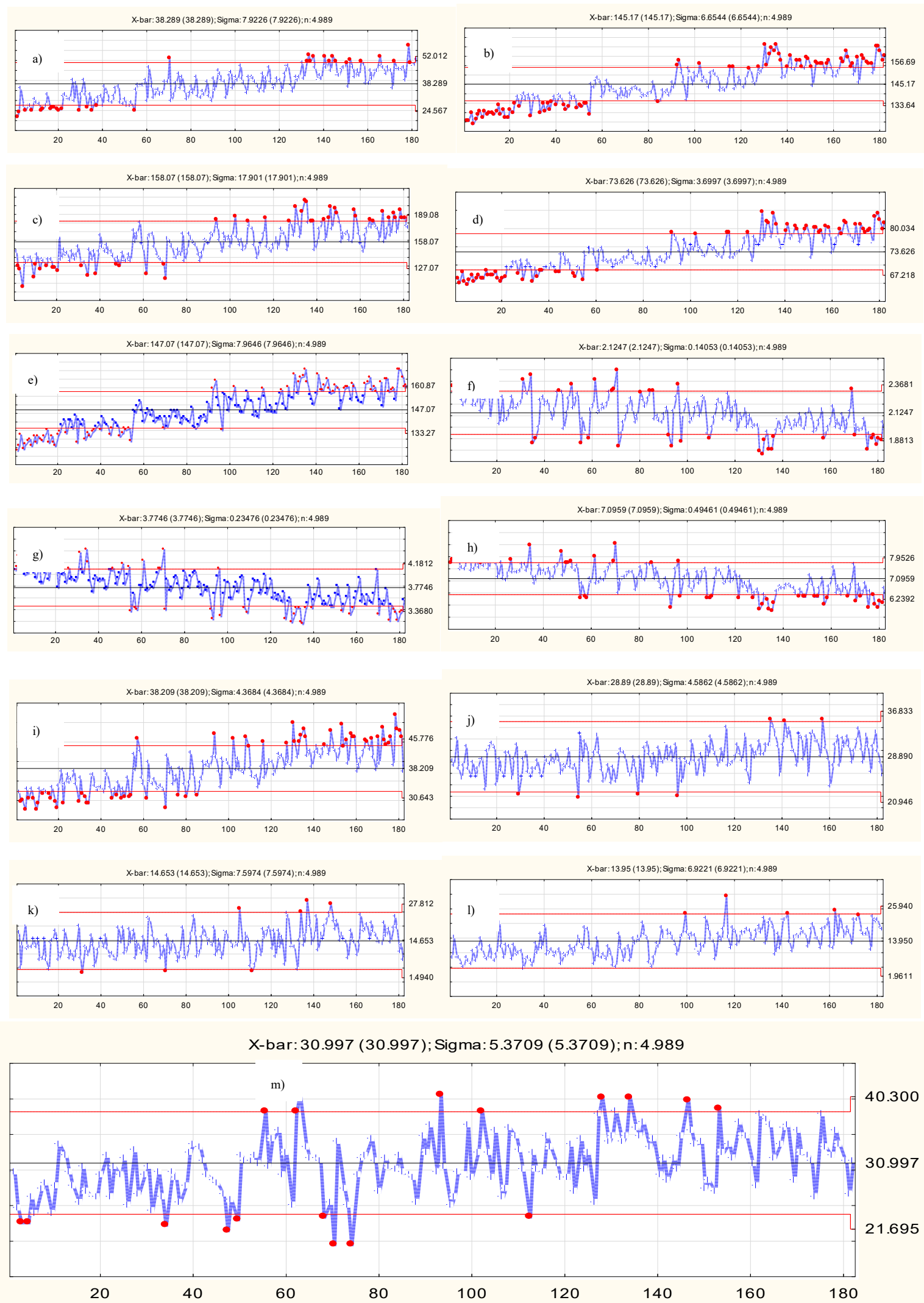

Fig.2. Control chart for male athletes; (a) Weight; (b) Height; (c) Sitting Height; (d) Armspan; (e) Standing Broad Jump; (f) 10 Meter Run; (g) 20 Meter Run; (h) 40 Meter Run; (i) Vertical Jump (j) Sit And Reach (k) Max Push Up (1) 1 Min Sit Up (m) Vo2max 

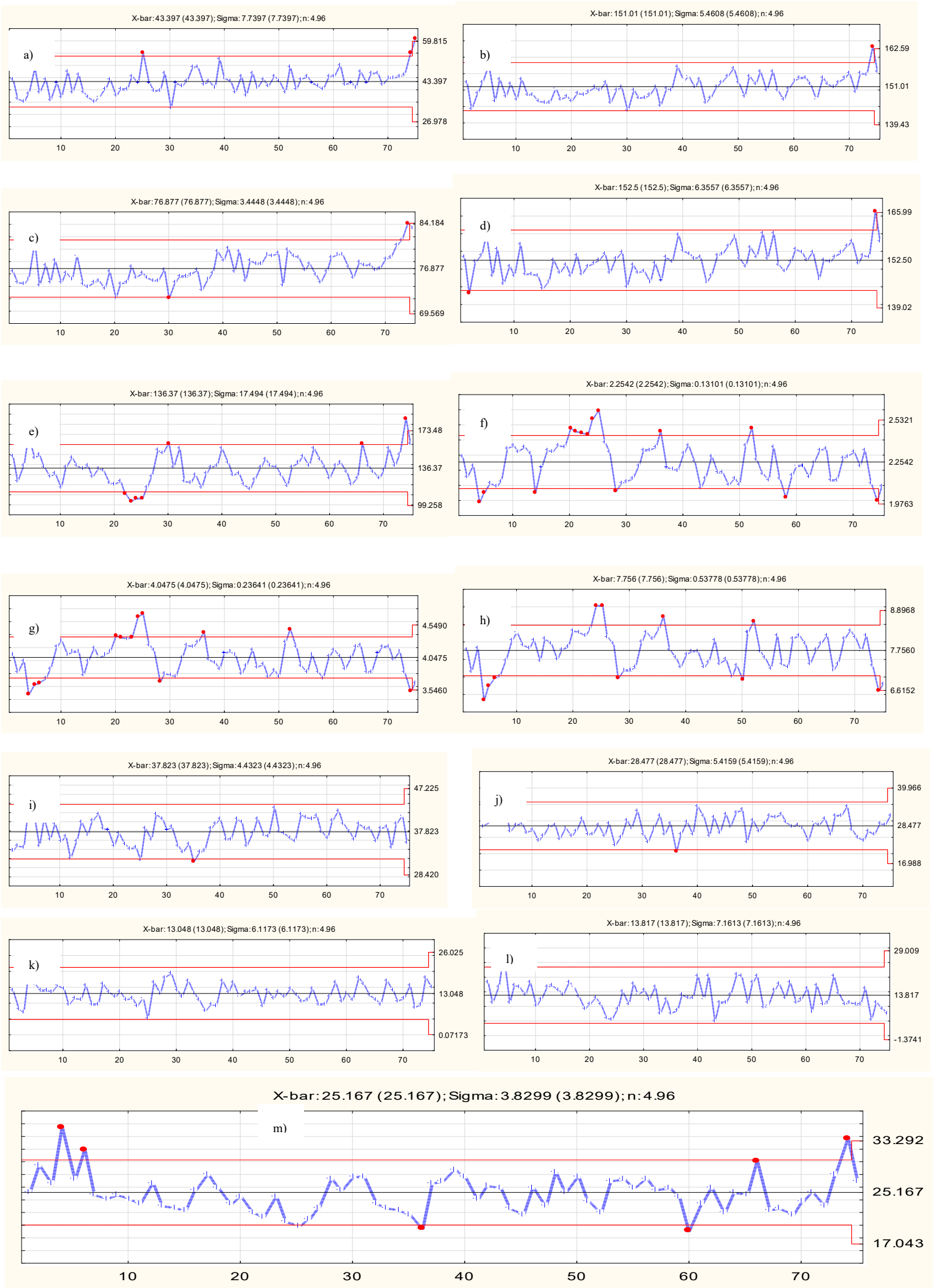

Fig.3. Control charts for female athletes; (a) Weight (b) Height (c) Sitting Height (d) Armspan (e) Standing Broad Jump (f) 10 Meter Run (g) 20 Meter Run (h) 40 Meter Run (i) Vertical Jump (j) Sit And Reach (k) Max Push Up (1) 1 Min Sit Up (m) Vo2max 


\subsection{Discussion}

Aim of the study is to establish scientific baseline of physical fitness and anthropometric on youth athletes at ages 7 . Talent identification programs are designed to identify young athletes, who possess extraordinary potential for excellent performances in senior elite sport and to select and recruit them into talent promotion programs [9].

\subsection{Significant Parameters}

Consequently, based on the finding of the current study demonstrated that anthropometric and physical fitness characteristics could be used to recognize talent identification among the men and women athletes at 13-15 years in all sports required.

The results showed that VFs with absolute values greater than 0.70 were standardized as the selection threshold due to the fact that these values are considerably solid and stable. VF1 from male athletes contributes about $33.24 \%$ of the variability and the strong positive factor loading parameters which is the distance speed test (10, 20 and 40 meters speed test) were found and can be rename as lower limb strength. The VF2 contributed about $64.47 \%$ and four significant parameters with strong negative factor loading namely weight, height, sitting height and armspan. Based on the finding, the new name for VF2 is physical fitness performances. The VF3 contributed $75 \%$ from max push up (0.76)that can be refer to as endurance that aim of this test is to perform as many push-ups in the participant which can requires the heart, lungs and blood system to provide oxygen to the working muscles throughout the game in any sports.

Process capability is the range over which the natural variation of the process occurs as determined by the system of common causes. In this study, the ability of the combination of athletes, power and the measurement to determine the actual capability of athlete's actual performances beyond the limit based on 13 parameters measured. In relation, the results from this study suggest that SPCs' physical characteristics do influence athletes' efficacy expectations regarding the potential effectiveness and their capabilities. These analysis monitor to the athlete in talent identification programs in such way to guide for the relative performances by carried out the control limit for each parameters that were contributed from male and female athletes. 


\section{CONCLUSION}

The current study has successfully identified the components of physical fitness related performance pattern similarities and variation among male and female athletes. Thus, this study achieved the objective of establish scientific baseline of physical fitness and anthropometric on youth athletes. Although most of the components of physical fitness discussed in this article could be required, certain specific components appeared to be more appropriate for the successful performance of one game than the other. However, the finding of this study can be useful for coaches and sports managers to determine and to recognize the physical fitness patterns, similarities and variations for both male and female athletes as this might help the coach and the trainers alike to structure training programs to suit the need of each game that were identified by significant indicator and normative baseline using capability control limit process instead of mean and standard deviation.

The findings of the present study can be valuable for coaches in determined the best athletes and sports managers that was used in determine the most significant performances of athletes. Hence, the SPC and PCA method can also be useful in filtering as well as the selection of athletes in any various sports.

\section{ACKNOWLEDGEMENTS}

The authors wish to acknowledge the coaches and managers of Institut Sukan Negara for their support to the accomplishment of this study. The authors thank the Research and Development Management Unit, University of Sultan Zainal Abidin (UniSZA), Kuala Terengganu for providing the research grant for the study (UnisZA/1/2017/ISN/3/RR179).

\section{REFERENCES}

[1] Abdullah M R, Maliki M, Husin A B, Musa R M, Kosni N A, Juahir H, Haque M. Multi-hierarchical pattern recognition of athlete's relative performance as a criterion for predicting potential athletes. Journal of Young Pharmacists, 2016, 8(4):463-470

[2] Abdullah M R, Musa R M, Kosni N A, Maliki A B, Karim M S, Haque M. Similarities and distinction pattern recognition of physical fitness related performance between amateur soccer 
and field hockey players. International Journal of Life science and Pharma Research, 2016, 6(4):L35-46

[3] Durand-Bush N, Salmela J H, Green-Demers I. The development of talent in sport. In R. N. Singer, H. A. Hausenblas, \& C. Janelle (Eds.), Handbook of sport psychology. New Jersey: John Wiley and Sons, 2001, pp. 269-289

[4] Ericsson K A, Krampe R T, Tesch-Römer C. The role of deliberate practice in the acquisition of expert performance. Psychological Review, 1993, 100(3):363-406

[5] Cripps A J, Hopper L, Joyce C. Maturity, physical ability, technical skill and coaches' perception of semi-elite adolescent Australian footballers. Pediatric Exercise Science, 2016, 28(4):535-541

[6] Hill B, Sotiriadou P. Coach decision-making and the relative age effect on talent selection in football. European Sport Management Quarterly, 2016, 16(3):292-315

[7] Louzada F, Maiorano A C, Ara A. iSports: A web-oriented expert system for talent identification in soccer. Expert Systems with Applications, 2016, 44:400-412

[8] G. Hoare D, Warr C R. Talent identification and women's soccer: an Australian experience. Journal of Sports Sciences, 2000, 18(9):751-758

[9] Vaeyens R, Güllich A, Warr C R, Philippaerts R. Talent identification and promotion programmes of Olympic athletes. Journal of Sports Sciences, 2009, 27(13):1367-1380

[10] Connes P, Sara F, Hardy-Dessources M D, Marlin L, Etienne F, Larifla L, Saint-Martin C, Hue O. Effects of short supramaximal exercise on hemorheology in sickle cell trait carriers. European Journal of Applied Physiology, 2006, 97(2):143-150

[11] Abbott A, Button C, Pepping G J, Collins D. Unnatural selection: Talent identification and development in sport. Nonlinear Dynamics, Psychology, and Life Sciences, 2005, $9(1): 61-88$

[12] Milistetd M, Ciampolini V, Salles W D, Ramos V, Galatti L R, Nascimento J V. Coaches' development in Brazil: structure of sports organizational programmes. Sports Coaching Review, 2016, 5(2):138-152

[13] Sarkar J, Saha S, Agrawal S. An efficient use of principal component analysis in workload characterization-A study. AASRI Procedia, 2014, 8:68-74 
[14] Zou C, Zhang Y, Wang Z. A control chart based on a change-point model for monitoring linear profiles. IIE Transactions, 2006, 38(12):1093-1103

[15] Leger L, Lambert J, Goulet A, Rowan C, Dinelle Y. Capacité aérobie des Québécois de 6 á 17 ans-test navette de 20 métres avec paliers de 1 minute. Canadian Journal of Applied Sport Sciences, 1984, 9(2):64-69

[16] Dona G, Preatoni E, Cobelli C, Rodano R, Harrison A J. Application of functional principal component analysis in race walking: An emerging methodology. Sports Biomechanics, 2009, 8(4):284-301

[17] Leporace G, Batista L A, Muniz A M, Zeitoune G, Luciano T, Metsavaht L, Nadal J. Classification of gait kinematics of anterior cruciate ligament reconstructed subjects using principal component analysis and regressions modelling. In Annual International Conference of the IEEE Engineering in Medicine and Biology Society, 2012, pp. 6514-6517

[18] Federolf P, Tecante K, Nigg B. A holistic approach to study the temporal variability in gait. Journal of Biomechanics, 2012, 45(7):1127-1132

[19] Manage A B, Scariano S M. An introductory application of principal components to cricket data. Journal of Statistics Education, 2013, 21(3):1-22

[20] Parmar M, Oberoi E H, Kalia E G, Kaur H. Diagnostic tools to revive sick manufacturing units using SPC (Statistical Process Control) technique: A review. International Research Journal of Engineering and Technology, 3(6):734-738

\section{How to cite this article:}

Adnan A, Abdullah MR, Juahir H, Maliki ABHM, Musa RM Mat-Rasid SM, Kosni NA.The identification of essential normative performances indicators for adolescent: an implication for talent identification programme. J. Fundam. Appl. Sci., 2017, 9(2S), 583-601. 